\title{
Equity, discrimination and remote policy: Investigating the centralization of remote service delivery in the Northern Territory
}

Authors: Francis Markham a b and Bruce Doran a b

a Centre for Aboriginal Economic Policy Research, The Australian National

University, 24 Kingsley Place, Acton ACT 2601, Australia

b Present address: Fenner School of Environment and Society, The Australian

National University, 48A Linnaeus Way, Acton ACT 2601, Australia

\section{Corresponding author:}

Francis Markham

francis.markham@anu.edu.au

Phone: +61488196318

This is an Accepted Manuscript of an article published by Elsevier in Applied Geography on 19 February 2015, available online: http://dx.doi.org/10.1016/j.apgeog.2015.01.020

This work should be cited as:

Markham, F., \& Doran, B. (2015). Equity, discrimination and remote policy: Investigating the centralization of remote service delivery in the Northern Territory. Applied Geography, 58, 105-115. doi:10.1016/j.apgeog.2015.01.020

\begin{abstract}
Two hypotheses have been advanced to explain the spatial patterning of service accessibility. The bureaucratic hypothesis holds that spatial inequalities are unpatterned and result from the application of decisions rules, while the competing political hypothesis suggests that politically-motivated decision making results in discriminatory outcomes. We use the example of the centralization of service provision in remote Indigenous communities in Australia's Northern Territory to show that these hypotheses may in fact be complementary. In recent years, government rhetoric about Australia's remote Indigenous communities has moved to focus on economic viability instead of social justice. One policy realization of this rhetoric has been the designation of 'growth towns' and 'priority communities' to act as service hubs for surrounding communities. The introduction of such hubs was examined and substantial inequality in access to service hubs was found. Inequality and overall system efficiency could be reduced with by optimizing the selection of hubs but the imposition of any hub-and-spoke mode in the study area was associated with racially-patterned patterned inequality of access. We conclude that when policy contexts are politically motivated, the application of racially-blind decision rules may result in racially-discriminatory spatial inequalities.
\end{abstract}

\section{Keywords}

spatial inequality; accessibility; service provision; centralization; remote Australia 


\section{Equity, discrimination and remote policy: Investigating the centralization of remote service delivery in the Northern Territory}

\section{Introduction}

Provision of public services is one of the fundamental roles of contemporary governments. However, whenever allocative decisions are made questions of equity inevitably arise. A vast literature documenting the spatial inequity of service provision has proliferated over recent years. One branch of literature is concerned with identifying locations that are underserviced so that resources can be directed appropriately. For example, Coffee et al. (2012) developed an index of access to cardiac services in Australia, finding that $14 \%$ of localities have poor access to relevant health services, suggesting an increased risk of mortality from cardiovascular diseases for residents of those areas. A similar logic underlies an immense set of studies in the domains of access to health services (for a review, see Rosenberg, 2014) and other services such as food retailing (McEntee \& Agyeman, 2010) or high-speed internet access (Riddlesden \& Singleton, 2014).

The geographic accessibility of services and amenities is important because accessibility may potentially impact on service use and thereby outcomes. Studies of the association between accessibility and health outcomes generally find mixed results. A recent meta-analysis of the relationship between access to greenspace and obesity found that most studies reported a weak correlation between health outcomes and greenspace accessibility, although results were inconsistent (Lachowycz \& Jones, 2011). In one typical study of health service accessibility, Astell-Burt et al. (2012) found that for people diagnosed with hepatitis C, those living further from a specialist treatment center were less likely to be referred. For those who were referred, however, travel distance to treatment was not correlated with non-attendance or loss to follow-up. Similarly, Wan et al. (2012) found that while access to oncologists was related to cancer survival in rural Texas, accessibility was not a salient factor in urban Texas. While the specific results in this vast literature vary among service types, outcome variables and study areas, the cumulative evidence suggests that service accessibility frequently impacts on outcomes in ways that are sometimes minor but often policy relevant.

Service accessibility thus becomes an issue of social and indeed spatial justice (Rosenberg, 2014). When inequalities of access exist and when accessibility influences outcomes, questions of 'who gets what, where and how' (Smith, 1974) take on a new urgency. Indeed, many studies have found that access to services is correlated with socio-economic advantage and race. For example, Hilmers et al. (2012) review of 24 studies found generally greater levels of neighborhood accessibility to unhealthy food outlets in deprived neighborhoods or neighborhoods with a greater proportion of residents from an ethnic minority. In Auckland, New Zealand, Sanders et al. (2013) found that the provision of private musculoskeletal clinics was concentrated in ethnically European neighborhoods, but that the provision of publicly-funded general practitioners was not racially patterned. Similarly, a national county-level analysis of the distribution of physician 
assistants and medical doctors in the United States found that levels of provision were greater in counties with a greater proportion of white, non-Hispanic residents (Shaffer \& Zolnik, 2014). What these exemplary studies reveal is that the accessibility of services that affect people's life chances is frequently distributed in racially and socially patterned ways.

Given that the geography of service delivery impacts on outcomes, questions should be raised about why such discriminatory spatial patterning exists. While this question has received relatively little attention in the geographic accessibility literature, it became a key issue among urban policy scholars following a Washington DC court finding the presence of discrimination in the distribution of school funding in 1967 (Oakley \& Logan, 2007). While most scholars have confirmed the existence of some degree of inequity in the distribution of urban services, the cause of misallocation has been the subject of much attention. Animating this debate has been an effort to discover whether discrimination-direct or indirect-has resulted in ethnic minorities or other disadvantaged groups receiving diminished access to services relative to the rest of the community.

Two competing hypotheses have been proposed to explain the creation and persistence of spatial inequity in service delivery. First, a political hypothesis has been proposed, in which elected officials misallocate services in order to ensure the loyalty of their voter base (e.g. Cingranelli, 1981). Alternatively phrased, the political hypothesis predicts that when it comes to service distribution 'some groups suffer because of their race, because of their social status or because of their paucity of political power' (Lineberry, 1977, p. 12). If this hypothesis holds, we should expect to find disadvantaged groups having relatively low levels of access to services.

The second hypothesis asserts that service allocation is largely a bureaucratic rather than political function and therefore suggests that because bureaucratic decisions are usually routinized and made without reference to race or class, there should be no systematic pattern to service delivery inequalities (e.g. Mladenka, 1989). Over three decades of empirical research among urban scholars, mostly in the United States, generally lent support to the bureaucratic hypothesis (Meier, Stewart, \& England, 1991), with some notably rare exceptions (e.g. Koehler \& Wrightson, 1987). Recent methodological advancements in Geographic Information Systems (GIS) and spatial analysis (Miyake, Maroko, Grady, Maantay, \& Arno, 2011; e.g. Talen \& Anselin, 1998) have done little to dislodge the conclusion among scholars of urban policy that the spatial distribution of service provision demonstrates 'unpatterned inequality' (Lineberry, 1977, p. 142), especially with respect to fixed infrastructure such as urban parks which cannot easily be relocated (Lineberry, 1977; Pallas \& Jennings, 2010). This literature has suffered, however, from an urban American bias and a relative disconnection from the vast body of geographic studies of accessibility discussed above.

In this paper we seek to advance the state of the literature examining the political and bureaucratic hypotheses using a novel research design that demonstrates that these two hypotheses and the dynamics they describe may in 
some cases be complementary rather than competitive. That is, we advance the thesis that the application of a bureaucratic set of decision rules may still result in racially-patterned service accessibility.

\section{Background}

Remote Australia is qualitatively different from much of the rest of Australia (Holmes, 1981). Remote Australia, as defined by the Australian Bureau of Statistics (ABS) Remoteness Structure, accounts for the more than 85 per cent of the national landmass that is located at a great distance to major centers of industry and commerce. It is characterized by a physical environment that is generally unattractive for agricultural activity aside from low-density rangeland pastoralism. In consequence, remote Australia is sparsely populated, inhabited by only 2.3 per cent of the Australian population, with a mean population density of just 1 person per $13.5 \mathrm{~km}$. Land use in this sparsely populated region is undergoing a multifunctional transition from pastoralism towards conservation, Indigenous and resource-extractive uses (Holmes, 2008). Although ownership of Australia was violently appropriated from its Indigenous people by the British Crown, land rights legislation and judicial decisions since 1966 have resulted in Indigenous ownership of 22 per cent of the Australian landmass being restored or recognized, almost all of which is located in remote parts of the country (Altman \& Markham, 2015).

The Northern Territory is perhaps the most remote jurisdiction in continental Australia, with a population of just 231,000 in 2011 , the majority of whom live in the capital Darwin (Australian Bureau of Statistics, 2013). Outside of Darwin, just 102,000 people occupy a remote hinterland of $1,345,000 \mathrm{~km}^{2}$. Over half of this remote population is Indigenous, mostly living in so-called 'discrete Indigenous communities' on land owned by formally-incorporated Aboriginal entities. These discrete communities, established due to Aboriginal social agitation for land rights and self-determination in the 1970s and 1980s, have enabled some Aboriginal people to move back to land from which they had been dispossessed. Remote communities now form a key part of remote Australia's settlement structure (Holmes, 1988), especially in the NT. In 2006, an estimated 63 per cent of the remote Indigenous population lived in 1,112 discrete Indigenous communities. ${ }^{1}$ These small settlements range from tiny 'homelands' populated by a handful of residents to larger remote towns of several thousand (see Figure 1). Discrete Indigenous communities usually occupied by Indigenous residents and a small minority of transient non-Indigenous staff. 


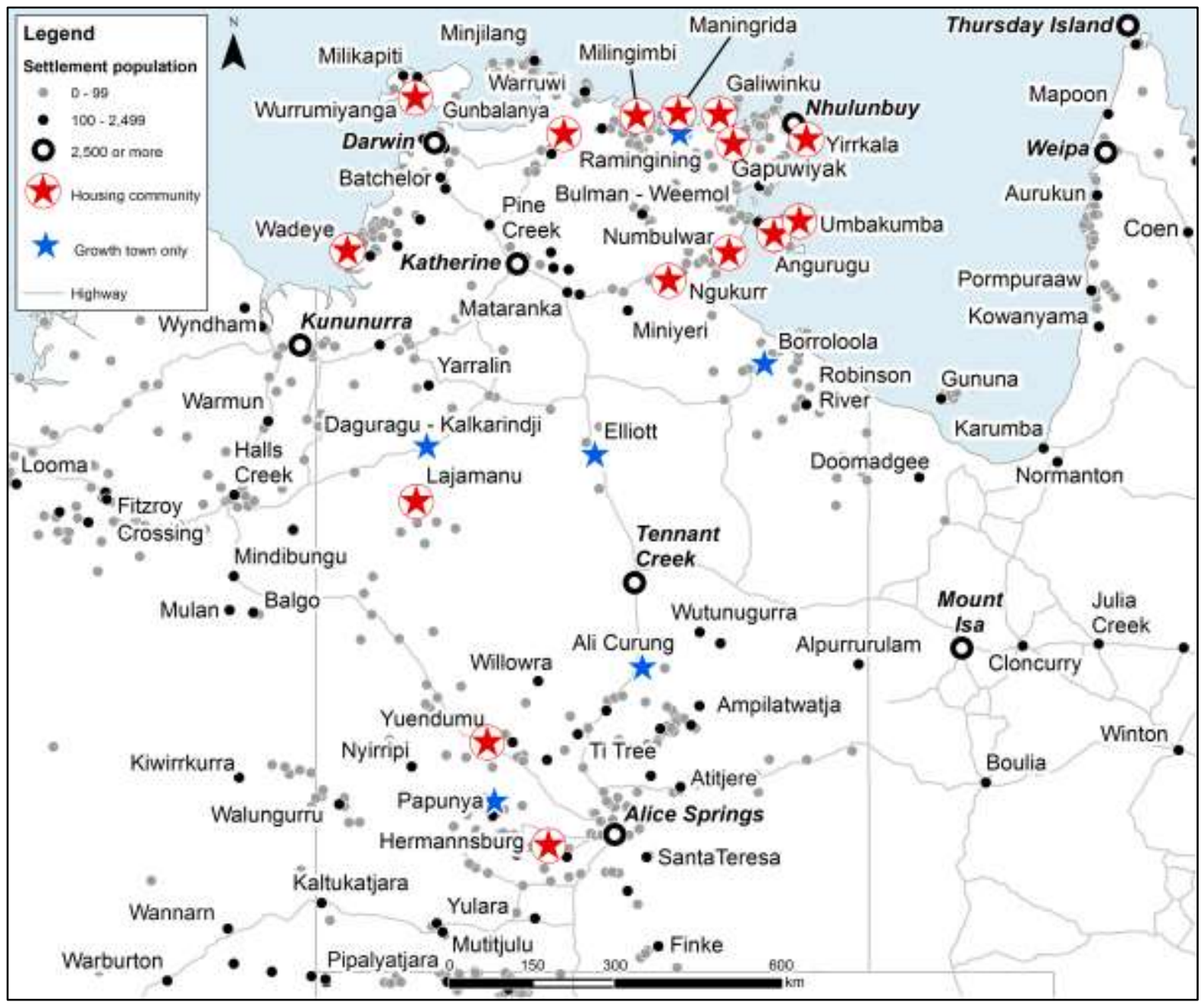

Figure 1 Northern Territory housing communities and growth towns.

Australia's remote discrete Indigenous communities are characterized by their relative inaccessibility and their distinctive economy, with a persistent customary economy, relatively little access to private-sector labor markets and encapsulation within a federal welfare state (Altman, 2001). In general, physical access to services is an acute problem for Indigenous residents of remote areas, with a nationally representative survey of Indigenous Australians finding that not only are basic facilities such as dentists and hospitals more difficult to access in remote areas than non-remote areas but also that access barriers in remote areas are more frequently related to physical access rather than other issues such as cost barriers or waiting times (Australian Bureau of Statistics, 2010).

These spatial factors and on-going settler colonialism combine to produce a range of negative economic, health and educational outcomes in remote communities. In conventional economic terms, Indigenous poverty levels are high. Around $48 \%$ of Indigenous families in remote Australia live below the poverty line, although there is a significant association between Indigenous poverty and remoteness only for couples (36\%; Hunter, 2012). These economic data should be 
considered with caution, however, as recorded incomes may be supplemented by non-market activities in remote areas (Altman, 2001). While for Indigenous Australians, the associations between health outcomes and remoteness vary according to health condition (Australian Institute of Health and Welfare, 2014b), accessibility of primary health services is far poorer in remote communities (Australian Institute of Health and Welfare, 2014a). While educational accessibility decreases with remoteness (Haberkorn \& Bamford, 2000), educational achievement decreases dramatically with remoteness even for primary school children (Department of Families, Housing, Community Services and Indigenous Affairs, 2013), the age at which the accessibility gradient is flattest.

Since 2005 both the federal and Northern Territory governments have reoriented their remote service delivery policies to focus on centralization. While centralization policies in remote Indigenous Australia hark back to the colonial-era forced sedentarization of nomadic hunter-gatherer people (e.g. Rowse, 1998), the current neocolonial centralization strategy in remote Indigenous Australia is couched in economic terms. Remote communities are described as economically 'unviable' (Altman, 2009; Moran, 2010), with their populations considered by one recent government review to be an impediment to the development of Northern Australia (Joint Select Committee on Northern Australia, 2014). Framing the residents of remote communities as welfare mendicants, the policy injunction of the state has been described by one observer as 'Transform the bush, rationalise, reorder!' (Rothwell, 2014).

Housing provision has been at the forefront of the rollout of centralization policies. Housing may have been selected as the initial policy locus because housing investments are long-term. Thus, by centralizing housing provision, path dependent concentration of other services is likely to follow. Following the abolition of the Indigenous representative body with a responsibility for service delivery in 2004 and the so-called 'mainstreaming' of responsibility for remote housing provision in the NT to a federal government department, a review of remote Indigenous housing provision recommended an overhaul of the funding system. Responsibility for remote housing was devolved the NT under a Memorandum of Understanding (MoU) signed by the NT and federal governments (Australian Government \& Northern Territory Government, 2007). The MoU asserted that new housing was to be prioritized for 'main urban centers and larger/strategically placed growth communities... to meet existing demand and future growth' while in 'smaller communities... new housing [is] to be negotiated and agreed on a case-bycase basis.' In outstations, the smallest remote Indigenous settlements, no new housing was to be funded. While MoU did not precisely specify what was meant by 'larger/strategically placed growth communities', fifteen communities in the NT were identified for the receipt of new housing (Auditor-General for the Northern Territory, 2010). While the federal partially resumed responsibility for new housing development later that year as part of a federal 'Intervention' into remote Indigenous communities in the NT (see Altman \& Hinkson, 2007), the selection of growth communities was retained. 
The centralization strategy pioneered in the NT was expanded to encompass a hub-and-spoke model for service delivery and extend across much of the rest of remote Australia as part of the agenda-setting 'Closing the Gap' National Partnership Agreement on Remote Service Delivery (Council of Australian Governments, 2009). In April 2009, Australian governments at state and federal levels agreed to prioritize the delivery of housing and selected social services to a further 14 communities outside the NT, bringing the number of so-called 'priority communities' to 29 nationally (Macklin, 2009). Residents of other communities would either have to do without infrastructure, or resort to migration or temporary mobility to access services (Moran, 2010). The non-NT communities were reportedly selected on the basis of the following four criteria (Macklin, 2009):

- Significant concentration of population;

- Anticipated demographic trends and pressures;

- The potential for economic development and employment; and

- The extent of pre-existing shortfalls in government investment in infrastructure and services.

The process by which these criteria were selected and their sometimes competing multiple criteria were balanced in order to select priority communities is unclear from the public record.

In May 2009, the NT government followed suit and announced that it would reorient its remote service delivery and regional development policies around the creation of 20 service hubs (Northern Territory Government, 2009). Once again, the 15 communities prioritized for housing were built upon, with the inclusion of a further 5 communities within the NT. New infrastructure and service spending would be prioritized in these new 'Growth Towns' as they were initially designated. Implicit in the allocation of service hubs was the expectation that service centralization would result in population growth via migration from communities in their hinterland (Taylor, 2009). Indeed, preliminary research suggests that service hub communities are relatively 'sticky' in terms of their ability to attract migrants from neighboring remote areas and to retain existing residents when compared to similar non-hub remote communities (Biddle \& Markham, 2013). Such stickiness may be a result of their relatively higher levels of housing and service provision. Nevertheless, it should be clear that these migration outcomes associated with service hubs do not equate to a successful 'growth pole' regional development strategy (Parr, 1999) but rather centralization through the diversion of a small portion of the flow of outbound migrants in remote areas.

The authors are not aware of any specific services being closed in non-hub communities in the Northern Territory as a result of the centralization policy. A recent government-commissioned review suggested the closure of remote secondary schools, to be replaced with a centralized system of boarding schools (Wilson, 2014), although this policy has not been implemented to date. As with housing, however, there is an historic undersupply of health and education services in most remote communities. The priority-community policy, which funnels resources to 
hub communities, is likely to result in poorer outcomes in non-hub communities which do not receive much needed investments in service provision.

The neighboring jurisdiction of Western Australia, however, has foreshadowed a radical program of closures. While this de facto commenced with the closure of services such as schools and health services in several non-'priority' communities (e.g. school closures in Patjarr: Ward, 2010), this policy has progressed to the closure of entire communities. One remote community, Oombulgurri, was recently closed after services were removed (Herbert, 2011), and its remaining inhabitants forced to leave (Vidot, 2014). Similar closures are reportedly planned for a further 150 communities (Herbert, 2014).

\section{Research approach}

While the rationalization of remote service delivery may be worthy of critique for normative reasons (Altman, 2009; Moran, 2010), this paper has different aims. From an applied perspective, this paper seeks to describe the geography of the service hubs in the Northern Territory and its relationship to spatial and racial inequalities through a series of four analyses. First, the current system of service hubs is described, showing which locations are most adversely affected in terms of travel time to nearest hub. Second, a rule-driven location-allocation analysis is used to generate a hypothetical system of service hubs that minimizes overall travel time to nearest service hub. Third, the actual and optimized systems of service hubs are compared, showing which areas are relatively well or poorly served by the current system of hubs. Finally, the current system of hubs, the optimized system of hubs, and the differences between the two systems are compared to the Indigenous population distribution to test for the existence of racially patterned or unpatterned inequality.

These analyses also inform a theoretical inquiry. Specifically, this paper seeks to reconcile two seemingly contradictory hypotheses regarding service distribution, the political hypothesis and the bureaucratic hypothesis, and show that they may in certain circumstances be complementary. The first analysis shows the existence of spatial inequalities in service provision under the current system of hubs. However, the conclusions that can be drawn about the causes of spatial inequalities are limited. Consequently, we augment this with the locationallocation analysis, which simulates a rule-driven, racially-blind allocation process consistent with the bureaucratic hypothesis. By comparing both these systems of hubs with the distribution of the Indigenous population, we demonstrate that both the actual system of hubs and the hypothetical rule-driven system of hubs discriminate against Indigenous people. We argue that this is because the imposition of any system of hubs is discriminatory, given the population geography of the Northern Territory. Therefore, we suggest that the decision to implement any centralization policy is consistent with the political hypothesis of racially discriminatory decision making, even if implemented with a bureaucratic rationality. We conclude that these apparently contradictory positions may co-exist, with political considerations operating at one spatial and regulatory scale and bureaucratic processes dominating at another scale. 


\section{Methods and materials}

\subsection{Travel time and service hub catchment estimation}

Travel time to the current service hub was estimated using a Geographic Information System (GIS). The residential locations of the NT population - or population origins - were approximated using the centroids of ABS Mesh Blocks for 2011. Mesh blocks are the smallest spatial unit at which the ABS release population counts, with a median residential population count of 48 (IQR $=0-$ 103). Because the population counts released at mesh block level are not disaggregated by Indigenous status and do not adjust for census undercount, mesh block populations were estimated by the authors by pro-rating the state-wide estimated residential population using NT-specific undercount factors adjusted for Indigenous status, five year age bracket and sex (Australian Bureau of Statistics, 2012). As a consequence of the NT's population sparsity, some populated remote Mesh Blocks are very large (the largest decile of populated NT Mesh Blocks range in size from $12 \mathrm{~km}^{2}$ to $70,406 \mathrm{~km}^{2}$ ), rendering centroid locations somewhat arbitrary origin points. In order to mitigate the effect of this instance of the Modifiable Areal Unit Problem (Hayward, 2009), the 639 discrete Indigenous communities in the NT as reported in the 2006 Community Housing and Infrastructure Needs Survey or CHINS (Australian Bureau of Statistics, 2007) were used instead of centroids as origin points in Mesh Blocks containing at least one community. When multiple CHINS communities were enveloped within a single Mesh Block, all communities were retained and the Mesh Block population estimate was pro-rated between them according to their 2006 populations.

Catchments of service hubs were estimated by finding the nearest service hub for each origin point, where service hubs included the NT's five major urban centers, the fifteen Housing Communities and six additional Growth Towns. Distance between origin points and service hubs was calculated using travel time driving at the speed limit along the road network, using a national road network dataset (StreetPro Australia, 2012). In order to include island populations in this model, public air transit and ferry services were included, using routes and timetables published on the internet or collected by telephone in February 2013. Travel time by airplane or ferry was calculated by summing actual transit time and the mean wait for a service between the hours 6:00 AM and 10:00 PM.

In order to capture cross-border servicing of NT residents, urban centers with a population of 5,000 or more in adjacent states were included in the model. This is important, as anecdotal accounts suggest that NT residents may access services in towns in WA, QLD and SA (most importantly Kununurra and Mount Isa). Because this paper is concerned with the accessibility of services for NT residents, residents of neighboring states who may access services in the NT were excluded from the analysis.

Travel time to nearest service hub was then estimated as a continuous surface across the state for cartographic purposes, using a travel time of 60 $\mathrm{km} /$ hour off the road network. 


\subsection{Location-allocation analysis of service hubs}

In order to assess the efficiency of the currently selected system of service hubs, the current system was compared with a hypothetical system of service hubs in which travel time is minimized. A location-allocation analysis was undertaken to identify this optimal system of reallocated service hubs. More specifically, the solver sought to minimize aggregate travel time in a $p$-medians problem, where all settlements in the NT with a population of 200 or more were considered candidate service hubs under the constraint that existing major urban centers in the NT and beyond its borders (i.e. towns with a population of 5,000 or more) always be selected as service hubs. Communities were weighted by population. Origin points were weighted by estimated residential population. In order to maintain consistency with the current system of service hubs, the number of service hubs to select was fixed at 21 . Because the number of potential systems of hubs is too large to exhaustively evaluate each possible combination, a heuristic approach (Teitz \& Bart, 1968) combined with Hillsman editing (1984) was used in ArcGIS 10.1.

Catchments in the optimized system of hubs were calculated and mapped using the same method as used for the current system of hubs. To estimate and locate the inefficiencies in the current system of hubs, the difference in travel times between the existing system of hubs and the hypothetical, optimized system was then calculated and mapped. These differences were summarized at the regional level using the ABS Indigenous Region statistical geography (see Figure 2), with the differences in mean travel time between the two systems of hubs estimated using linear regression for each Indigenous Region. 


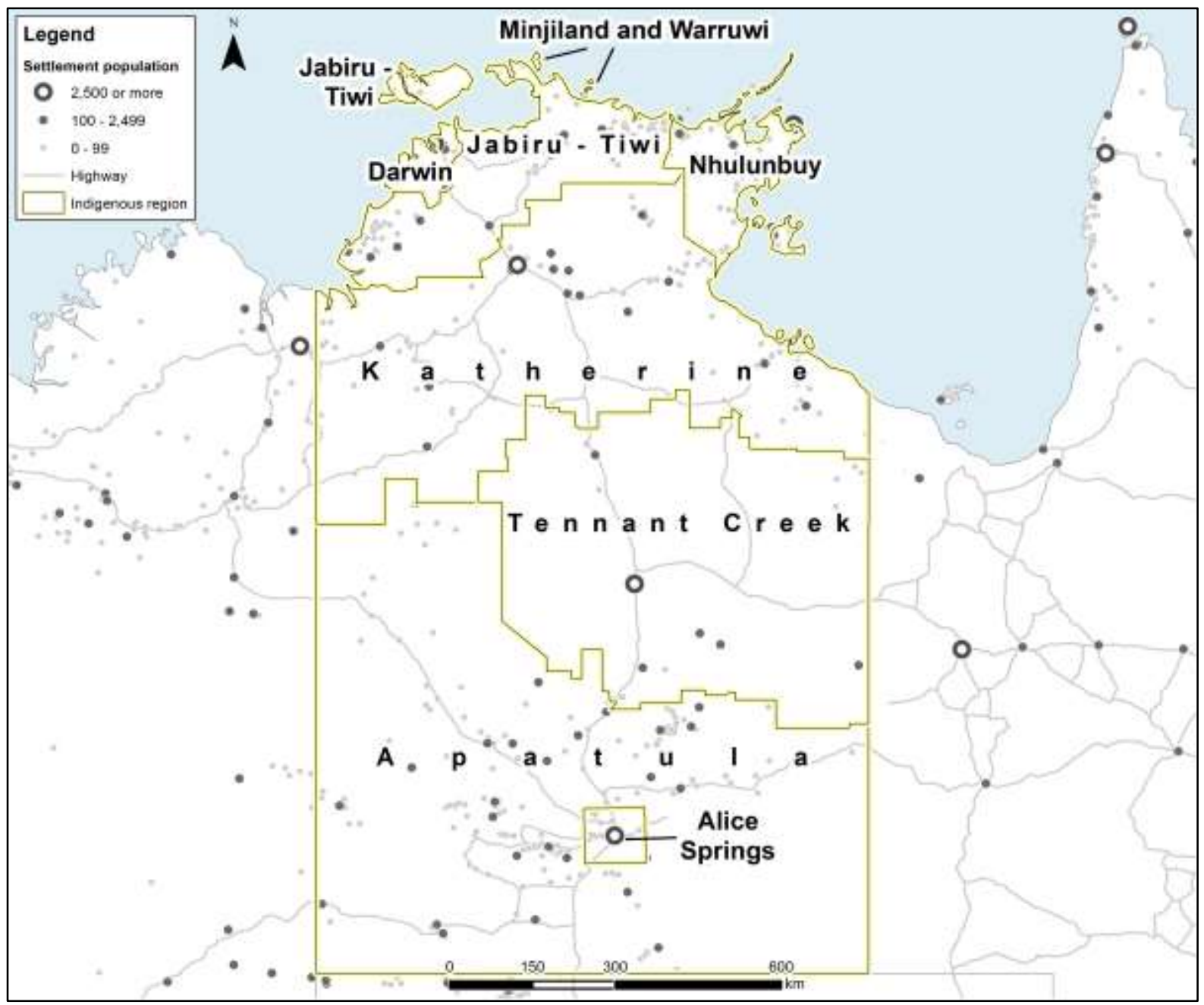

Figure 2 ABS Indigenous regions and settlements in the Northern Territory.

\subsection{Testing unpatterned inequality}

In order to test the unpatterned inequality hypothesis, a group who might be discriminated against in the allocation of urban services must be identified. This paper tests the hypothesis that Indigenous residents of the non-urban NT receive a lower level of service accessibility than their non-Indigenous counterparts. To do so, three multivariate regression analyses of travel time are conducted from origin points to nearest hub. In Model 1, the travel time to nearest hub in the current system of hubs was used as the dependent variable. The proportion of residents who identified in the 2011 census as Indigenous (at the SA1 level) was an independent variable to test for a systematic difference between Indigenous and non-Indigenous NT residents. Settlement size was included as a covariate to account for the possibility that settlement size (W. Sanders, 2010) as well as Indigenous status was determinative of travel time. Origin points were weighted by their estimated residential population. Outlier origin points with very large travel times (due to being isolated on islands) were excluded from this analysis as they artificially inflated model fit results, but their exclusion did not impact on the sign or significance of coefficient estimates. 
It is possible that Indigenous residents of the NT must travel for longer to reach a service hub than non-Indigenous residents because they live further from major urban centers. To test if this was the case, a second regression analysis (Model 2) was conducted using travel time to nearest service hub in the optimized system of service hubs as the dependent variable and the same independent variables. Finally, to account for this potential effect, the analysis was repeated using the difference in travel time between the two systems of hubs as the independent variable.

\section{Results}

\subsection{Current service hub catchments and travel time}

A substantial heterogeneity in both the travel time to service hubs and their populations is evident. Darwin, the NT's capital and largest settlement also has the largest catchment (see Error! Reference source not found.). It is the major center or growth town for over 21,700 people. Katherine, Alice Springs and Ali Curung have the next largest catchments, being the closest service hub for over 6,100, 4,800 and 2,800 people respectively. Hermannsburg, Papunya and Ali Curung have the most dispersed service catchments, with a mean travel time for those in the catchment of 2:13, 2:01 and 1:32 respectively. When these travel times are mapped (see Error! Reference source not found.), it is evident that accessibility to service hubs in lowest in the southern part of the state, although some island settlements in the north such as Warruwi and Minjilang also suffer from low access to service hubs.

\subsection{Optimized service hub catchments and travel time}

The optimized service hub system retained most of the current service hubs (see Figure 4). Towns that lost their hub status were Ali Curung, Daguragu - Kalkarinji, Elliot, Numbulwar, Papunya, Umbakumba and Yirrkala. In the cases of Umbakumba and Yirrkala, their deselection was due to the proximity of other service hubs at Angurugu and Nhulunbuy, while in the other cases deselection was likely due to a more systemic realignment. Current non-hub towns that were selected as service hubs were Ampilatwatja, Minjilang, Ti Tree, Walungurru, Warruwi, Yarralin and Yulara. In the cases Minjilang and Warruwi, their island status means that air travel is the only available mode of transport to any service hub. Therefore, despite their relatively small town and catchment populations (see Error! Reference source not found.) their contribution to total travel time to hubs still contributed significantly to the state total.

In this optimized system of hubs, travel time to the nearest hub remains highly uneven (see Figure 4). Large areas of very low accessibility would still be found in the far southeast of the state, in addition to pockets of low accessibility in the Tanami desert, the Gulf of Carpentaria and Arnhem Land. 
Table 1 Major urban centre, housing community and growth town catchments and travel times by service hub.

Current system of hubs

\begin{tabular}{|c|c|c|c|c|c|c|c|c|}
\hline \multirow[b]{2}{*}{ Settlement } & & \\
\hline & $\begin{array}{l}\text { Mean } \\
\text { travel } \\
\text { time } \\
\end{array}$ & $\begin{array}{l}\text { Max } \\
\text { travel } \\
\text { time } \\
\end{array}$ & $\begin{array}{c}\text { Town } \\
\text { Population }\end{array}$ & $\begin{array}{l}\text { Catchment } \\
\text { population }\end{array}$ & $\begin{array}{l}\text { Mean } \\
\text { travel } \\
\text { time } \\
\end{array}$ & $\begin{array}{l}\text { Max } \\
\text { travel } \\
\text { time } \\
\end{array}$ & $\begin{array}{c}\text { Town } \\
\text { Population }\end{array}$ & $\begin{array}{l}\text { Catchment } \\
\text { population }\end{array}$ \\
\hline Ali Curung & $1: 32$ & $3: 25$ & 645 & 2,898 & - & - & - & - \\
\hline Alice Springs & $0: 14$ & $3: 46$ & 26,206 & 4,824 & $0: 11$ & $3: 46$ & 26,206 & 4,301 \\
\hline Ampilatwatja & - & - & - & - & $1: 11$ & $3: 14$ & 436 & 2,129 \\
\hline Angurugu & $0: 11$ & $1: 11$ & 1,003 & 1,468 & $0: 15$ & $1: 11$ & 1,003 & 2,021 \\
\hline Borroloola & $0: 35$ & 4:06 & 1,107 & 954 & $0: 35$ & $4: 06$ & 1,107 & 954 \\
\hline Daguragu & $0: 57$ & $2: 44$ & 641 & 730 & - & - & - & - \\
\hline Darwin & $0: 22$ & $19: 38$ & 110,074 & 21,713 & $0: 15$ & $2: 11$ & 110,074 & 20,826 \\
\hline Elliott & $0: 21$ & $3: 15$ & 406 & 192 & - & - & - & - \\
\hline Galiwinku & $0: 03$ & $0: 29$ & 2,549 & 219 & 0:03 & $0: 29$ & 2,549 & 219 \\
\hline Gapuwiyak & $0: 44$ & $2: 28$ & 1,055 & 1,083 & $0: 44$ & $2: 28$ & 1,055 & 1,083 \\
\hline Gunbalanya & $0: 25$ & $2: 12$ & 1,404 & 1,704 & $0: 25$ & $2: 12$ & 1,404 & 1,704 \\
\hline Hermannsburg & $2: 13$ & $6: 33$ & 746 & 2,003 & $0: 51$ & $2: 33$ & 746 & 1,595 \\
\hline Katherine & $0: 20$ & $4: 20$ & 6,520 & 6,120 & $0: 19$ & $2: 44$ & 6,520 & 6,087 \\
\hline Lajamanu & $0: 07$ & $3: 17$ & 760 & 37 & $0: 40$ & $3: 17$ & 760 & 752 \\
\hline Maningrida & 0:07 & $1: 17$ & 2,752 & 424 & 0:07 & $1: 17$ & 2,752 & 424 \\
\hline Milingimbi & 0:01 & 0:03 & 1,296 & 42 & $0: 01$ & 0:03 & 1,296 & 42 \\
\hline Minjilang & - & - & - & - & 0:02 & $0: 33$ & 369 & 5 \\
\hline Ngukurr & $0: 36$ & $2: 10$ & 1,260 & 823 & $0: 52$ & 4:09 & 1,260 & 1,634 \\
\hline Nhulunbuy & 0:02 & 0:08 & 4,260 & 172 & 0:07 & $2: 15$ & 4,260 & 1,365 \\
\hline Numbulwar & 0:01 & $1: 16$ & 807 & 1 & - & - & - & - \\
\hline Papunya & $2: 01$ & $6: 04$ & 496 & 1,477 & - & - & - & - \\
\hline Ramingining & $0: 28$ & $2: 49$ & 1,057 & 588 & $0: 28$ & $2: 49$ & 1,057 & 588 \\
\hline Tennant Creek & $0: 12$ & $3: 15$ & 3,354 & 416 & $0: 34$ & $3: 18$ & 3,354 & 1,180 \\
\hline Ti Tree & - & - & - & - & $0: 54$ & $2: 54$ & 143 & 1,439 \\
\hline Umbakumba & $0: 02$ & $0: 37$ & 540 & 13 & - & - & - & - \\
\hline Wadeye & $0: 31$ & $2: 25$ & 2,547 & 1,832 & $0: 31$ & $2: 25$ & 2,547 & 1,832 \\
\hline Walungurru & - & - & - & - & $0: 35$ & $2: 05$ & 538 & 210 \\
\hline Warruwi & - & - & - & - & $0: 01$ & 0:01 & 514 & 0 \\
\hline Wurrumiyanga & $0: 15$ & $1: 08$ & 1,875 & 1,224 & $0: 15$ & $1: 08$ & 1,875 & 1,224 \\
\hline Yarralin & - & - & - & - & $1: 02$ & $3: 52$ & 314 & 755 \\
\hline Yirrkala & $0: 14$ & $2: 10$ & 1,017 & 175 & - & - & - & - \\
\hline Yuendumu & $1: 16$ & $3: 45$ & 816 & 1356 & $0: 56$ & $3: 45$ & 816 & 755 \\
\hline Yulara & - & - & - & - & $0: 53$ & $2: 45$ & 860 & 1,043 \\
\hline
\end{tabular}




\subsection{Comparison of current and optimized service hubs}

If the current system of service hub were replaced with the optimized system, the landscape of travel time to the nearest hub would be substantially changed (see Figure 5). Total mean travel can be reduced from 25 minutes to 19 minutes. The most extreme example of this is in Minjilang and Warruwi, where currently residents must catch a light airplane to Darwin to access a service hub. On the other hand, in the towns of Darwin and Alice Springs almost no change in travel time is observed.

Beyond these outlying islands substantial scope to reduce aggregate travel time remains. Even if Minjilang and Warruwi and the large urban centers of Darwin and Alice Springs are removed from the analysis, the optimization of service hub allocations reduces mean travel time for the remaining 70,000 NT residents from 37 to 31 minutes. In Numbulwar and its hinterland travel time would be increased, with the closest service center now being Ngukurr. The relocation of a hub from Daguragu-Kalkarindji to Yarralin moved the location of an accessible region from the former to the latter, while residents of Elliot and its hinterland would suffer reduced hub accessibility, needing to travel to Tennant Creek to access their closest service hub. While residents of Ali Curung and its immediate hinterland

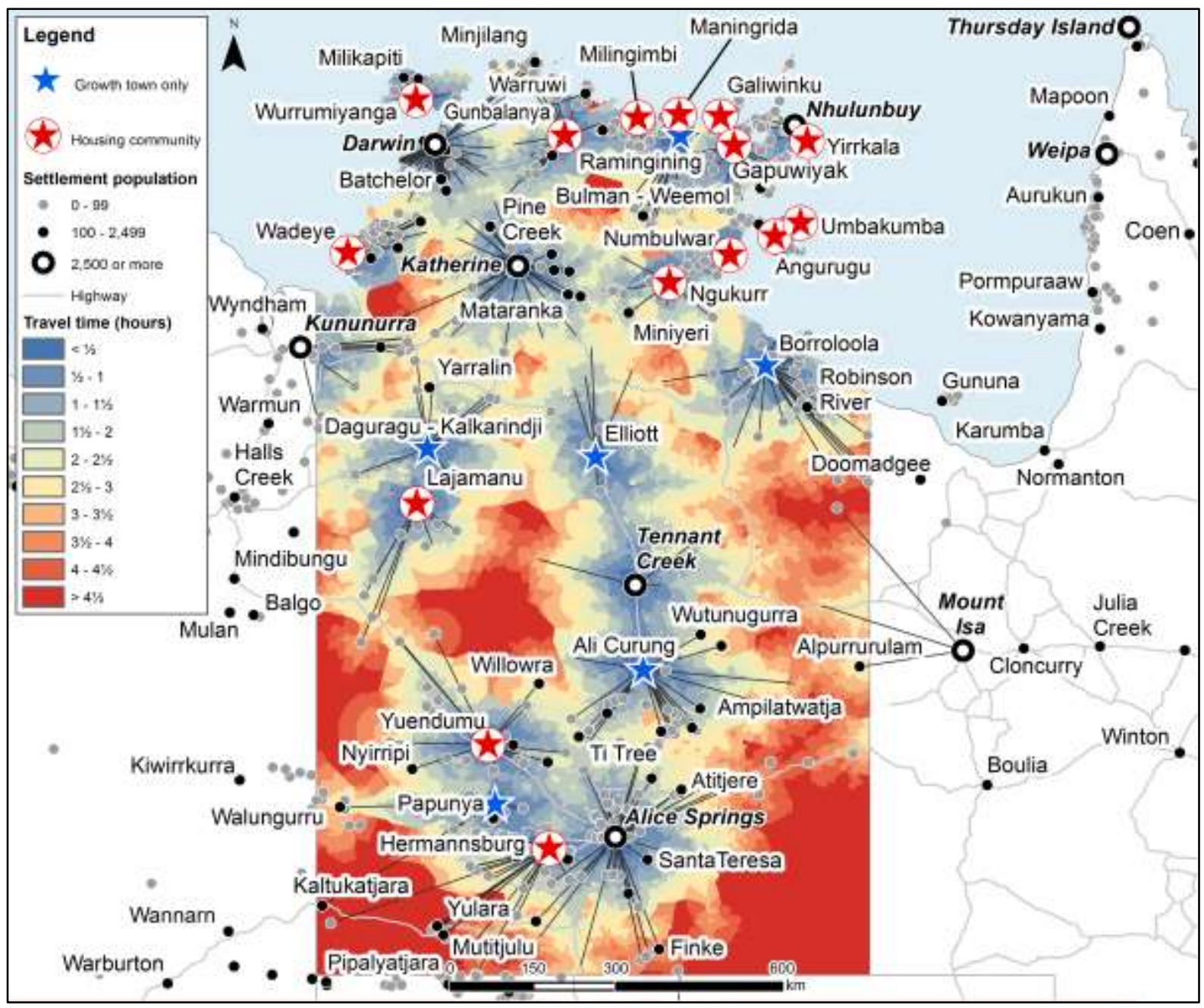

Figure 3 Travel time to nearest NT Housing Community or Growth Town. 
would also have reduced accessibility of service hubs, a much larger surrounding region would have increased access to service hubs. The largest region of increased accessibility would be in the south-west of the state, with residents of the large triangular region from Walungurru to Kaltukatjara and Yulara having much improved access to service hubs.

At the Indigenous Region level, the difference in travel time between the two systems of hubs is substantial in specific locations (see Table 1). For example, in the Alice Springs, Darwin, and Jabiru - Tiwi (excluding Minjilang and Warruwi) regions there was no change in travel time. In the Katherine, Nhulunbuy and Tennant Creek regions there were minor but statistically insignificant decreases in travel time, while in Minjilang and Warruwi and Apatula there were substantial and significant decreases in travel time.

Despite these decreases, substantial variation in average travel time to the nearest hub remained at the regional level after optimizing service hub location. While average travel time to the nearest hub in Apatula and Tennant Creek was almost one hour, in the Nhulunbuy region it was just fifteen minutes.

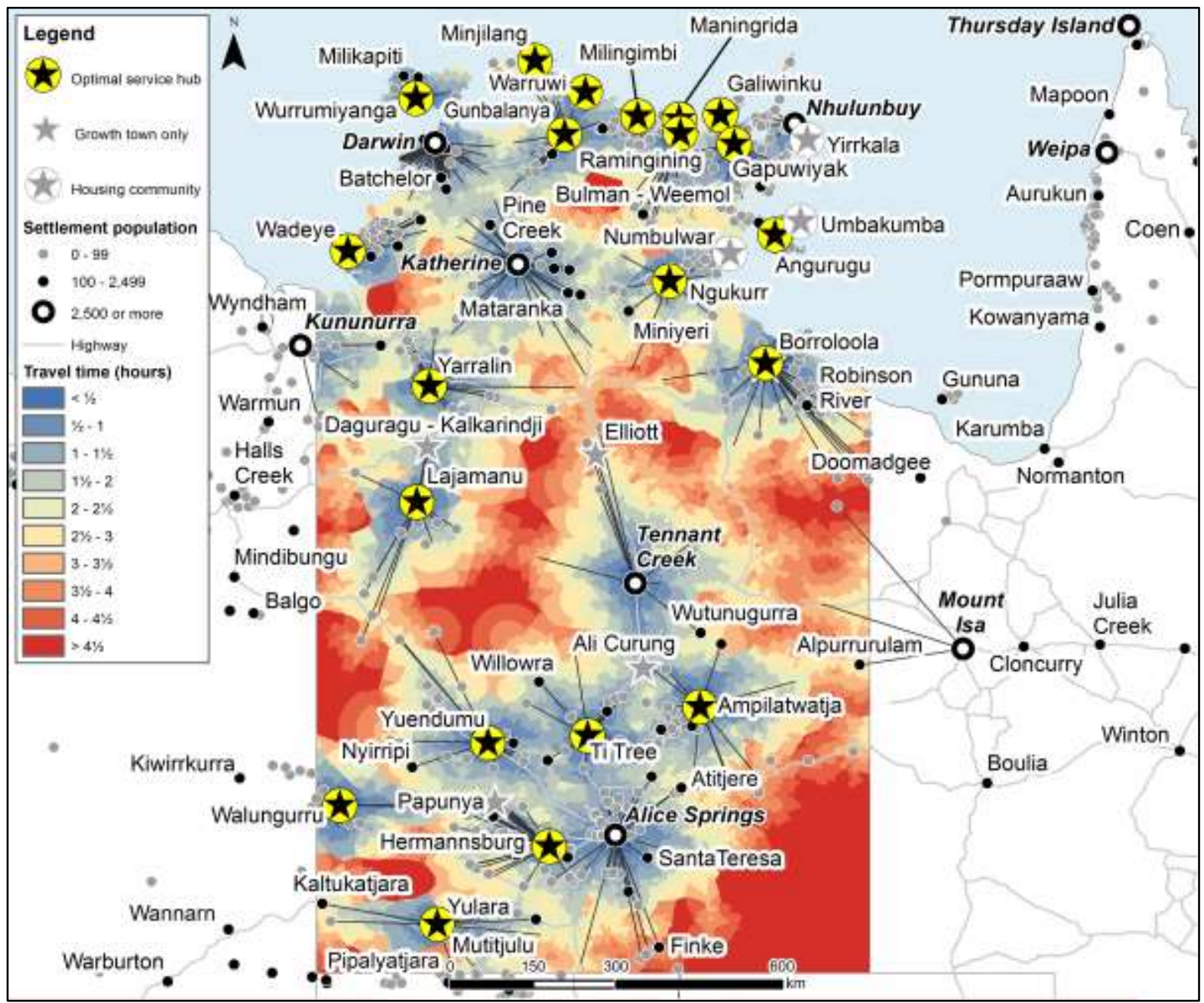

Figure 4 Travel time to optimal service hubs. 


\subsection{Patterned or unpatterned inequality}

Multiple regression of travel time to nearest hub against per cent Indigenous and settlement size revealed small but statistically significant associations with both covariates in both systems of hubs (see Table 3). For both the current system of hubs (Model 1) and the optimized system of hubs (Model 2), for every 10 per cent of the population that is Indigenous, estimated travel time increased by 3 minutes. Conversely, as the population of a settlement increased by 1,000 persons, travel time to the nearest hub decreased by 36-37 minutes. Neither of these factors predicted the difference in travel time that could be saved by reallocating service hubs (Model 3). As such, our results support hypothesis 2, that while unpatterned inequality may characterize the selection of particular hubs, the introduction of an efficient system of hubs is itself discriminatory.

\section{Discussion and conclusions}

The development of a system of service hubs entails the creation of significant spatial inequality in access to services. While this is most extreme for residents of islands who must use air or sea transport to access a service hub, substantial variations in accessibility remain even on the mainland. For example, while some

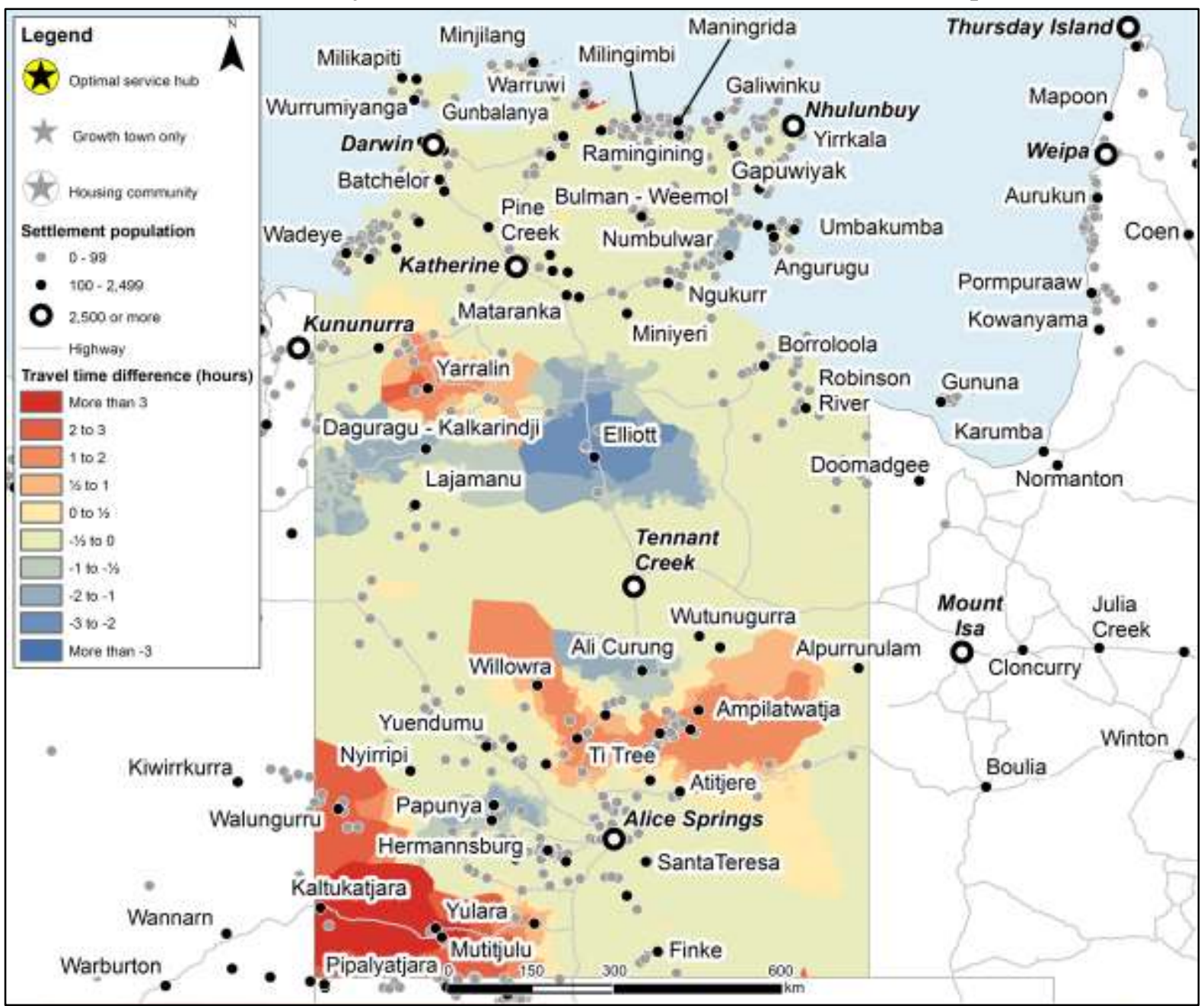

Figure 5 Difference in travel time between current system of hubs and optimized system of hubs. 
Table 1 Mean and maximum travel time to nearest hub by region of origin.

\begin{tabular}{|c|c|c|c|c|c|c|}
\hline \multirow[b]{2}{*}{ Indigenous region } & \multicolumn{3}{|c|}{ Mean travel time } & \multicolumn{2}{|c|}{ Maximum travel time } & \multirow[b]{2}{*}{ Population } \\
\hline & $\begin{array}{l}\text { Current } \\
\text { system of } \\
\text { hubs }\end{array}$ & $\begin{array}{c}\text { Optimised } \\
\text { system of } \\
\text { hubs }\end{array}$ & $p$ & $\begin{array}{c}\text { Current } \\
\text { system of } \\
\text { hubs }\end{array}$ & $\begin{array}{c}\text { Optimised } \\
\text { system of } \\
\text { hubs }\end{array}$ & \\
\hline Alice Springs & $0: 06$ & $0: 06$ & 1 & $0: 12$ & $0: 12$ & 27,313 \\
\hline Apatula & $1: 40$ & $0: 52$ & $<0.001$ & $6: 33$ & $4: 27$ & 12,662 \\
\hline $\begin{array}{l}\text { Darwin } \\
\text { Jabiru - Tiwi }\end{array}$ & $0: 15$ & $0: 15$ & 1 & $2: 07$ & $2: 07$ & 130,379 \\
\hline $\begin{array}{l}\text { (excluding Minjiland } \\
\text { and Warruwi) }\end{array}$ & $0: 24$ & $0: 24$ & 1 & $2: 25$ & $2: 25$ & 14,983 \\
\hline $\begin{array}{l}\text { Katherine } \\
\text { Minjilang and }\end{array}$ & $0: 28$ & $0: 28$ & 0.845 & $4: 20$ & $4: 09$ & 19,336 \\
\hline Warruwi & $18: 48$ & 0:01 & $<0.001$ & $19: 38$ & $0: 33$ & 999 \\
\hline Nhulunbuy & 0:09 & $0: 15$ & 0.098 & $2: 28$ & $2: 28$ & 16,930 \\
\hline Tennant Creek & $0: 39$ & $0: 59$ & 0.058 & $4: 34$ & $4: 34$ & 6,466 \\
\hline All & $0: 25$ & $0: 19$ & $<0.001$ & $19: 38$ & $4: 27$ & 229,068 \\
\hline
\end{tabular}

Table 2 Association between Indigenous status and travel time.

\begin{tabular}{|c|c|c|c|}
\hline & $\begin{array}{l}\text { Model } 1 \\
\text { Minutes to nearest } \\
\text { current hub }\end{array}$ & $\begin{array}{c}\text { Model } 2 \\
\text { Minutes to nearest } \\
\text { optimised hub }\end{array}$ & $\begin{array}{l}\text { Model } 3 \\
\text { Minutes saved by } \\
\text { reallocating hubs }\end{array}$ \\
\hline Constant & $47.7(41.3,54.0)^{* * *}$ & $39.3(34.9,43.7)^{* * *}$ & $8.5(2.8,13.9)$ ** \\
\hline Per cent Indigenous & $0.3(0.2,0.4)^{* * *}$ & $0.3(0.2,0.4)^{* * *}$ & $-0.0(-0.1,0.0)$ \\
\hline Settlement size ('000s) & $-36.8(-42.7,-30.9)^{* * *}$ & $-36.0(-40.1,-31.9)^{* * *}$ & $-0.9(-6.1,4.4)$ \\
\hline$R^{2}$ & 0.15 & 0.25 & 0.00 \\
\hline
\end{tabular}


residents in the far south west of the state are more than four and a half hours from a service hub, those living in mainland Arnhem Land are all within two and a half hours of the nearest service hub. Residents of major centers such as Darwin or Alice Springs need travel only within the town itself to access services. The current system of service hubs has imposed a gradient of accessibility across settlements in the Northern Territory. In towns unfortunate enough to be located at the terminus of a very long 'spoke', significant investment in public transport may be required as a starting point to mitigate this relative disadvantage. Central Australia, particularly the Utopia region and Western Desert are currently particularly poorly served, as are the island communities of Minjilang and Warruwi. Given the associations in the geographic literature between service accessibility and health and educational outcomes, we might expect residents of those areas which are poorly provisioned to do relatively worse. Our analysis suggests that attention to service accessibility in these locations may be warranted.

Furthermore, while any hub-and-spoke system will always produce some relatively inaccessible localities, it is important to note that the current system of hubs as whole is highly inefficient in terms of the aggregate travel time required for all residents to access their closest service hub. The reorganization of service hubs could reduce aggregate travel time by over $15 \%$ in remote areas, even when excluding remote islands. As such, this analysis demonstrates once again the potential for spatially-enabled governance to deliver superior outcomes (Hugo, 2001). We would expect service use to increase relative to the current system under such a reorganization, and as such, health and education outcomes to improve. However, relative to universal service provision in all communities, we would still expect to see a relative decline in outcomes.

When the Indigenous status of residents is compared with travel time to nearest hub, three results are found (see Table 3). First, travel time to nearest hub is greater in areas with a greater proportion of Indigenous residents. Second, this racially-patterned inequality is repeated in the optimized system of hubs, created by following racially-blind location-allocation analysis. Third, the difference in travel times between these two systems of hubs is not correlated with the Indigeneity of residents.

These important findings are worth repeating: while the current system of hubs is discriminatory, so too is a system created following the kind of decision rules suggested by the bureaucratic hypothesis. Yet this kind of patterned inequality is precisely what the bureaucratic hypothesis predicts should not exist. How is racially-patterned inequality created by following bureaucratic decision rules to be understood?

We suggest that in this specific instance, the apparent contradiction explained by the Indigenous population geography of the Northern Territory. Indigenous people in the Northern Territory are more likely to live in more remote, sparsely populated areas. These are precisely the areas that are most difficult to service equitably with a hub-and-spoke model. Any centralization strategy in this geographic context is in practice racially discriminatory, even if hubs are selected 
via a racially-blind decision process. Indeed, given that this centralization strategy is specific in its application to remote Indigenous communities (Rothwell, 2014), it can be argued that the overall policy of centralization and its spatial extent are themselves discriminatory. As such, one prominent commentator has described the centralization of services for Indigenous communities as an infrastructure apartheid system' (Mundine in Karvelas \& Taylor, 2014). The designation of 'priority communities' for service delivery is not in fact an effort to close the gap in socio-economic outcomes between Indigenous and non-Indigenous Australians but is instead revealed as a neocolonial policy of racially-discriminatory population management, justified with recourse to economic efficiency and implemented through rational bureaucratic processes.

More generally, politically discriminatory decisions can be implemented in a racially-blind, rational manner that leads to racially discriminatory outcomes. As the case of centralization in the Northern Territory shows, there is not necessarily a contradiction between the bureaucratic and political hypotheses regarding service inequality. Rational, racially-blind logics can create discriminatory outcomes when put in service to racially discriminatory policies.

\section{Notes}

1 This should be considered an approximation only, as the numerator population is sourced from ABS CHINS while the denominator comes from the ABS ERP.

\section{Acknowledgements}

The authors would like to thank Nick Biddle, Sandra Potter, Nicola Sloan and participants at the Institute of Australian Geographers conference in 2013 for their critical comments on an early version of this manuscript. 


\section{References}

Altman, J. (2001). Sustainable development options on Aboriginal land: The hybrid economy in the twenty-first century (Discussion Paper No. 226). Canberra: Centre for Aboriginal Economic Policy Research, ANU.

Altman, J. (2009, June 24). Still searching for a 'cogent' outstations policy for the NT. Charles Darwin University, Darwin.

Altman, J., \& Hinkson, M. (2007). Coercive reconciliation: stabilise, normalise, exit Aboriginal Australia. Melbourne: Arena Publications Association.

Altman, J., \& Markham, F. (2015). Burgeoning Indigenous land ownership: Diverse values and strategic potentialities. In S. Brennan, M. Davis, B. Edgeworth, \& L. Terrill (Eds.), Native Title From Mabo to Akiba: A Vehicle for Change and Empowerment?. Sydney: Federation Press.

Astell-Burt, T., Flowerdew, R., Boyle, P., \& Dillon, J. (2012). Is travel-time to a specialist centre a risk factor for non-referral, non-attendance and loss to follow-up among patients with hepatitis C (HCV) infection? Social Science \& Medicine, 75(1), 240-247. doi:10.1016/j.socscimed.2012.02.046

Auditor-General for the Northern Territory. (2010). Strategic Indigenous Housing and Infrastructure Program: June 2010 Report to the Legislative Assembly. Darwin: Legislative Assembly of the Northern Territory.

Australian Bureau of Statistics. (2007). Housing and Infrastructure in Aboriginal and Torres Strait Islander Communities, Australia, 2006 (cat. no. 4710.0). Canberra. Retrieved from http://www.abs.gov.au/ausstats/abs@.nsf/mf/4710.0

Australian Bureau of Statistics. (2010). The Health and Welfare of Australia's Aboriginal and Torres Strait Islander Peoples, Oct 2010 (cat. no. 4704.0). Canberra. Retrieved from http://www.abs.gov.au/ausstats/abs@.nsf/mf/4704.0 
Australian Bureau of Statistics. (2012). Census of Population and Housing - Details of Undercount, 2011 (cat. no. 2940.0). Canberra. Retrieved from http://www.abs.gov.au/ausstats/abs@.nsf/mf/2940.0

Australian Bureau of Statistics. (2013). Estimates of Aboriginal and Torres Strait Islander Australians, June 2011 (cat. no. 3238.0.55.001). Canberra.

Retrieved from

http://www.abs.gov.au/ausstats/abs@.nsf/mf/3238.0.55.001

Australian Government, \& Northern Territory Government. (2007). Memorandum of understanding between the Australian Government and the Northern Territory Government Indigenous housing, accommodation and related services.

Retrieved from

http://www.aph.gov.au/Parliamentary_Business/Committees/Senate_Com mittees?url=indig_ctte/submissions/sub28_attachment_8.pdf

Australian Institute of Health and Welfare. (2014a). Access to primary health care relative to need for Indigenous Australians. Canberra: AIHW.

Australian Institute of Health and Welfare. (2014b). Australia's Health 2014: The 14th biennial health report of the Australian Institute of Health and Welfare. Canberra: AIHW.

Biddle, N., \& Markham, F. (2013). Mobility (2011 Census Papers No. 9). Canberra: Centre for Aboriginal Economic Policy Reseach, The Australian National University.

Cingranelli, D. L. (1981). Race, Politics and Elites: Testing Alternative Models of Municipal Service Distribution. American Journal of Political Science, 25(4), 664-692. doi:10.2307/2110758

Coffee, N., Turner, D., Clark, R. A., Eckert, K., Coombe, D., Hugo, G., ... Tonkin, A. A. (2012). Measuring national accessibility to cardiac services using 
geographic information systems. Applied Geography, 34, 445-455.

doi:10.1016/j.apgeog.2012.01.007

Council of Australian Governments. (2009). National partnership agreement on remote service delivery. Canberra. Retrieved from http://www.federalfinancialrelations.gov.au/content/national_partnership_a greements/indigenous/remote_service_delivery/national_partnership.pdf

Department of Families, Housing, Community Services and Indigenous Affairs. (2013). Closing the Gap: Prime Minister's Report 2013. Canberra: FaHCSIA. Haberkorn, G., \& Bamford, E. (2000). Servicing regional Australia: a GIS study of accessibility to services in non-metropolitan Australia. Canberra: Bureau of Rural Sciences.

Hayward, P. M. (2009). The modifiable areal unit problem (MAUP) and health disparities. University of Connecticut. Retrieved from http://digitalcommons.uconn.edu/dissertations/AAI3367358

Herbert, B. (2011, February 28). Store closure puts future of remote community in doubt Store closure puts future of remote community in doubt. Australian Broadcasting Corporation Transcripts. Retrieved from http:/ / global.factiva.com/redir/default.aspx?P=sa\&an=ABCTRS0020110228 e72s000bc\&cat $=a \& e p=A S E$

Herbert, B. (2014, December 8). Remote Aboriginal communities face closure, leaders voice concerns. Australian Broadcasting Corporation Transcripts. Retrieved from http://global.factiva.com/redir/default.aspx?P=sa\&an=ABCTRS0020141208 eac80008r\&cat $=a \& e p=A S E$

Hillsman, E. L. (1984). The p-median structure as a unified linear model for location - allocation analysis. Environment and Planning A, 16(3), 305 - 318. doi:10.1068/a160305 
Hilmers, A., Hilmers, D. C., \& Dave, J. (2012). Neighborhood Disparities in Access to Healthy Foods and Their Effects on Environmental Justice. American Journal of Public Health, 102(9), 1644-1654.

doi:10.2105/AJPH.2012.300865

Holmes, J. H. (1981). Introduction. In R. E. Lonsdale \& J. H. Holmes (Eds.), Settlement systems in sparsely populated regions: the United States and Australia (pp. 1-12). New York: Pergamon.

Holmes, J. H. (1988). Remote settlements. In R. L. Heathcote (Ed.), The Australian Experience: Essays in Australian land settlements and Resource Management, Melbourne: Longman Cheshire (pp. 68-84). Melbourne: Longman Cheshire Pty Ltd.

Holmes, J. H. (2008). Impulses towards a multifunctional transition in rural Australia: Interpreting regional dynamics in landscapes, lifestyles and livelihoods. Landscape Research, 33(2), 211-223. doi:10.1080/01426390801912089

Hugo, G. (2001). Addressing Social and Community Planning Issues with Spatial Information. Australian Geographer, 32(3), 269-293. doi:10.1080/00049180120100022

Hunter, B. (2012). Is Indigenous poverty different from other poverty? In B. Hunter \& N. Biddle (Eds.), Survey Analysis for Indigenous Policy in Australia: Social Sciences Perspectives (pp. 193-221). Canberra: ANU Press.

Joint Select Committee on Northern Australia. (2014). Inquiry into the Development of Northern Australia - Final Report. Canberra: Commonwealth of Australia. Retrieved from http://www.webcitation.org/6VxEeNm2W Karvelas, P., \& Taylor, P. (2014, November 14). WA remote closures 'apartheid'. The Australian, p. 6. 
Koehler, D. H., \& Wrightson, M. T. (1987). Inequality in the Delivery of Urban Services: A Reconsideration of the Chicago Parks. The Journal of Politics, 49(01), 80-99. doi:10.2307/2131135

Lachowycz, K., \& Jones, A. P. (2011). Greenspace and obesity: a systematic review of the evidence. Obesity Reviews, 12(5), e183-e189. doi:10.1111/j.1467789X.2010.00827.x

Lineberry, R. L. (1977). Equality and urban policy: the distribution of municipal public services. Beverly Hills, Calif: Sage Publications.

Macklin, J. (2009, April 21). Speech to the John Curtin Institute of Public Policy. The John Curtin Institute of Public Policy, Perth. Retrieved from http://jennymacklin.fahcsia.gov.au/node/886

McEntee, J., \& Agyeman, J. (2010). Towards the development of a GIS method for identifying rural food deserts: Geographic access in Vermont, USA. Applied Geography, 30(1), 165-176. doi:10.1016/j.apgeog.2009.05.004

Meier, K. J., Stewart, J., \& England, R. E. (1991). The Politics of Bureaucratic Discretion: Educational Access as an Urban Service. American Journal of Political Science, 35(1), 155-177. doi:10.2307/2111442

Miyake, K., Maroko, A., Grady, K., Maantay, J., \& Arno, P. (2011). Not Just A Walk in The Park: methodological improvements for determining environmental justice implications of park access in New York City for the promotion of physical activity. Cities and the Environment (CATE), 3(1). Retrieved from http:/ / digitalcommons.lmu.edu/cate/vol3/iss $1 / 8$

Mladenka, K. R. (1989). The Distribution of an Urban Public Service The Changing Role of Race and Politics. Urban Affairs Review, 24(4), 556-583. doi:10.1177/004208168902400405

Moran, M. (2010). The Viability of 'Hub' Settlements. Dialogue, 29(1), 38-51. 
Northern Territory Government. (2009). Territory Growth Towns. Retrieved 7 January 2013, from http://web.archive.org/web/20090530090653/http://www.workingfuture.n t.gov.au/download/working_future_growth_towns.pdf

Oakley, D. A., \& Logan, J. R. (2007). A Spatial Analysis of the Urban Landscape: What Accounts for Differences across Neighborhoods? In L. M. Lobao, G. Hooks, \& A. R. Tickamyer (Eds.), The sociology of spatial inequality (pp. 215230). Albany: State University of New York Press.

Pallas, A. M., \& Jennings, J. L. (2010). A Multiplex Theory of Urban Service Distribution: The Case of School Expenditures. Urban Affairs Review, 45(5), 608-643. doi:10.1177/1078087409356757

Parr, J. B. (1999). Growth-pole Strategies in Regional Economic Planning: A Retrospective View Part 2. Implementation and Outcome. Urban Studies, 36(8), 1247-1268. doi:10.1080/0042098992971

Riddlesden, D., \& Singleton, A. D. (2014). Broadband speed equity: A new digital divide? Applied Geography, 52, 25-33. doi:10.1016/j.apgeog.2014.04.008

Rosenberg, M. (2014). Health geography I Social justice, idealist theory, health and health care. Progress in Human Geography, 38(3), 466-475. doi:10.1177/0309132513498339

Rothwell, N. (2014, November 15). Remote prospects of rejuvenation. The Australian, p. 21.

Rowse, T. (1998). White Flour, White Power: From Rations to Citizenship in Central Australia. Cambridge, UK: Cambridge University Press.

Sanders, L. J., Aguilar, G. D., \& Bacon, C. J. (2013). A spatial analysis of the geographic distribution of musculoskeletal and general practice healthcare clinics in Auckland, New Zealand. Applied Geography, 44, 69-78. doi:10.1016/j.apgeog.2013.07.014 
Sanders, W. (2010). Working Future: A critique of policy by numbers (Working paper No. 72). Canberra: Centre for Aboriginal Economic Policy Reseach, The Australian National University. Retrieved from http://caepr.anu.edu.au/Publications/WP/2010WP72.php

Shaffer, R., \& Zolnik, E. (2014). The geographic distribution of physician assistants in the US: Clustering analysis and changes from 2001 to 2008. Applied Geography, 53, 323-331. doi:10.1016/j.apgeog.2014.06.027

Smith, D. M. (1974). Who gets what where, and how: a welfare focus for human geography. Geography, 59(4), 289-297.

StreetPro Australia. (2012). (Version 2012.04). Pitney Bowes.

Talen, E., \& Anselin, L. (1998). Assessing spatial equity: an evaluation of measures of accessibility to public playgrounds. Environment and Planning A, 3O(4), 595 - 613. doi:10.1068/a300595

Taylor, J. (2009). Social Engineering and Indigenous Settlement: Policy and Demography in Remote Australia. Australian Aboriginal Studies, (1), 4-15.

Teitz, M. B., \& Bart, P. (1968). Heuristic Methods for Estimating the Generalized Vertex Median of a Weighted Graph. Operations Research, 16(5), 955-961.

Vidot, A. (2014, September 22). Campaigns ramp up to save buildings in abandoned WA community. Retrieved 29 January 2015, from http:/ /www.abc.net.au/pm/content/2014/s4092608.htm

Wan, N., Zhan, F. B., Lu, Y., \& Tiefenbacher, J. P. (2012). Access to healthcare and disparities in colorectal cancer survival in Texas. Health \& Place, 18(2), 321329. doi:10.1016/j.healthplace.2011.10.007

Ward, T. (2010, May 29). School closure a major blow. Kalgoorlie Miner, p. 4.

Wilson, B. (2014). Review of Indigenous Education in the Northern Territory: Draft Report. Darwin: Northern Territory Department of Education. Retrieved from http://www.webcitation.org/6VxCZ1PoU 
Equity, discrimination and remote policy 